\title{
Разработка информационной системы для гостиницы
}

\author{
Родионов Д.Н., студент, \\ Технический институт (филиал) \\ Северо-Восточного федерального университета, \\ 2. Нерюнгри \\ E-mail: flatron.dream@yandex.ru
}

Научный руководитель: к.т.н., доцент Похорукова М.Ю.

Тенденции перехода на автоматизированные системы весьма актуальны в условиях все более возрастающей конкуренции между предприятиями сферы услуг и требованиями клиента. Информационная система для гостиниц предназначена для автоматизации процесса управления гостиницей, включает в себя множество функций, среди которых: управление персоналом, бронирование номеров, обеспечение безопасности, расчет с гостями и т.д.

Представленная в статье информационная система предназначена для использования в гостиницах, хостелах, апартаментах, санаториях, базах отдыха, общежитиях и других заведениях гостиничного типа и обеспечивает следующие возможности:

• поиск, добавление, изменение и удаление сведений о клиентах, сотрудниках или номерах;

- сортировка информации в таблицах;

- регистрация новоприбывших клиентов;

- бронирование номеров;

- учет занятых, свободных и забронированных номеров.

Для реализации этих функций была разработана база данных, содержащая всю необходимую информацию (рис. 1). Работа с созданной базой данных осуществляется посредством сервера FireBird. Firebird - компактная, кроссплатформенная, свободная система управления базами данных (СУБД), работающая на Linux, Microsoft Windows и разнообразных Unix платформах. В качестве преимуществ Firebird можно отметить многоверсионную архитектуру, обеспечивающую параллельную обработку оперативных и аналитических запросов, компактность, высокую эффективность и мощную языковую поддержку для хранимых процедур и триггеров [1]. В качестве среды программирования была выбрана Embarcadero RAD Studio 2010 [2]. 


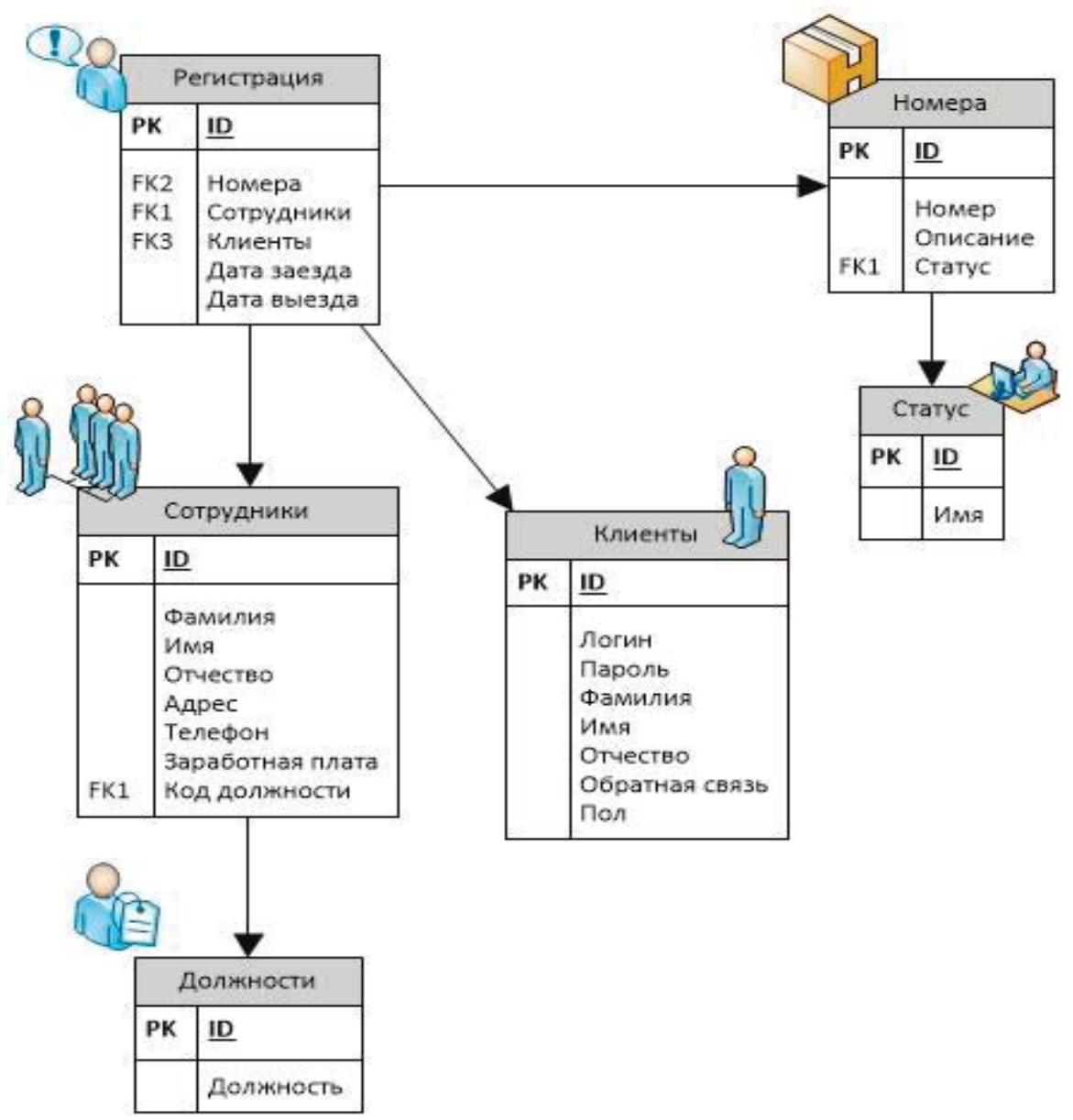

Рис. 1. Структура базы данных

На рисунке 2 представлено главное окно разработанной информационной системы: 


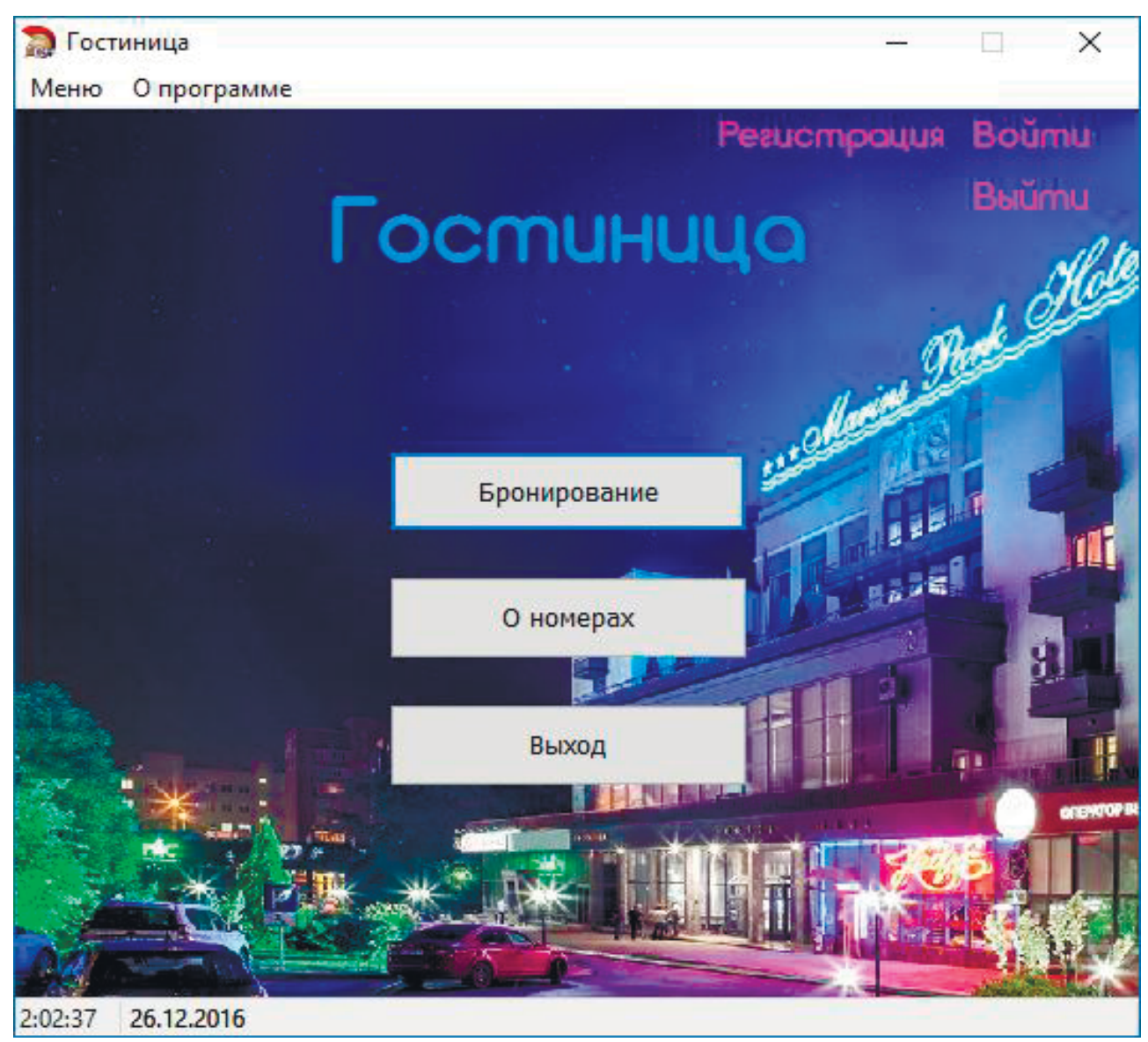

Рис. 2. Главное окно информационной системы «Гостиница»

Одной из отличительных черт разработанной программы является возможность бронирования. При нажатии на данную кнопку «Бронирование» появится новое окно (рис. 3), в котором пользователь может забронировать свободный номер, представленный в списке. При условии, что он ввел необходимую информацию в поля (выбранный номер, фамилия) и нажал на кнопку «Забронировать». Если пользователь удачно забронировал номер, соответствующие данные будут выведены в таблицу «Забронированные» которая находится в данном окне. Если пользователь заранее вошел в систему, то его фамилия будет автоматически помещена в поле фамилия. 


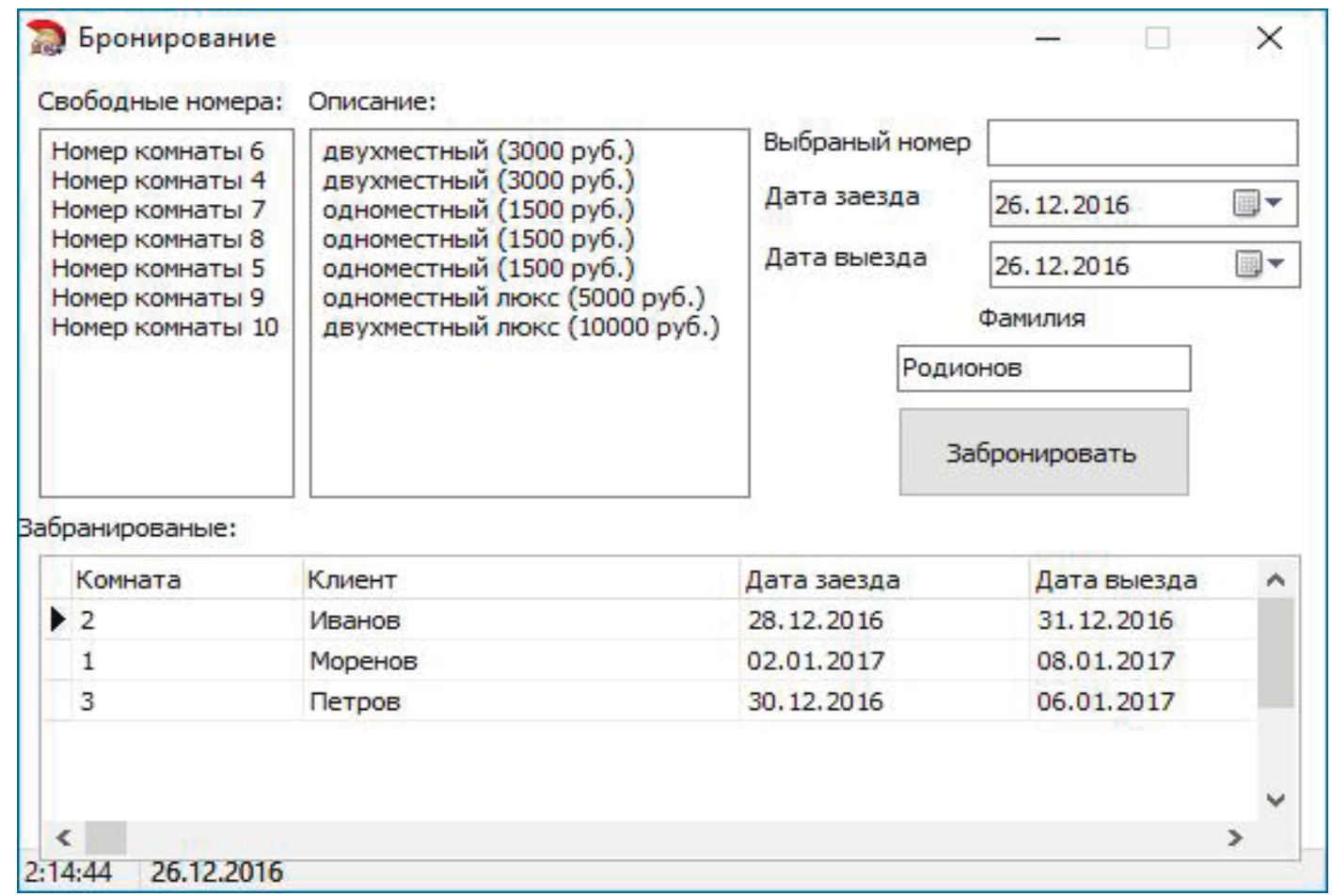

Рис. 3. Окно информационной системы для бронирования номера

Разработанное приложение получилось эффективным и надежным в своей работе, простым и удобным в эксплуатации, доступным любому пользователю в понимании. Преимущества данной информационной системы:

- простой функциональный интерфейс;

- простота использования;

- программа работает на любых ЭВМ, на которых возможна работа с реляционными базами данных;

- обеспечена целостность данных;

- время поиска, выдачи и обработки информации минимально (данный параметр будет зависеть от объема информации, хранящейся в БД);

- безграничность номерного фонда;

- удобный режим бронирования.

В дальнейшем данное приложение можно модернизировать, добавив следующие функции:

- работу с другими базами данных;

- автоматическую смену статуса номеров при выселении;

- вход в программу с использованием данных из «ВКонтакте»;

- добавление отзывов о гостинице.

Список литературы:

1. Узнайте все о Firebird за 2 минуты [Электронный pecypc] // Carlos H. Cantu версия 1.3, февраль 2010 года URL: http://www.firebirdnews.org/docs/fb2min_ru.html (дата обращения: 09.02.2017).

2. Embarcadero RAD Studio 2010 [Электронный ресурс] // Программирование Паскаль (Pascal) и Делфи (Delphi) // URL: http://delphi-box.ru/embarcadero-rad-studio2010.html (дата обращения: 09.02.2017). 